\title{
Vocational Secondary Schools in Malta: quality of education and the reproduction of inequality
}

\author{
RONALD G. SULTANA \\ Faculty of Education, University of Malta
}

\begin{abstract}
This article sets out to evaluate the quality of educational provision offered in vocational secondary schools in Malta. The economic and political context whlch saw the setting up of trade schools in the early 1970 s is described, and an account of the educational goals for these new schools, intended to rekindle the motivation for learning in low and non-achieving students, is offered. The article then explores the extent to which these goals were achieved, particularly through the examination of three related areas, namely the form (the status of trade schools as separate educational institutions), the content (the curriculum) and the process (classroom processes and instructional methods) evinced in these schools. The article concludes by arguing that the failure of trade schools to provide a worthwhile educational experience has to be located in the relationship between mental and manual work in the wider social order, and that the problems identlfied in this article could be endemic to vocational schooling at the secondary school level and are therefore not necessarily context-bound.
\end{abstract}

\section{Introduction}

This article examines two ways in which the creation of an educational space which purports to cater for the special needs of 'non-academic' students can in fact turn out to work against the educational - and ultimately economic - interests of that group. The key problem raised, therefore, relates to what is perhaps the most fundamental contemporary challenge facing formal educational systems: how does one cater for differences in culture, class, gender, learning styles and abilities in student without at the same time condemning these same students to marginality? The challenge is to acknowledge and value difference without, on the one hand, excluding groups or, on the other hand, including them on a 
nominal basis. Such a nominal inclusion leads, in fact, to the exclusion of students from the more valuable educational programmes and consequently from higher status educational and economic rewards.

Inter- and intra-school streaming, comprehensives, vocational and special schooling and tracks, one and all represent ways in which different educational systems have addressed the challenge of catering for students who are - or who are constructed as being - different. Malta [1] has faced this challenge in different ways. After a brief and unsuccessful flirt with middle school comprehensives in the early 1970s, the Maltese secondary school system reverted to selective and exclusionary practices (Sultana, 1991), distributing 'academically successful' students into private schools or state junior lyceums, those less so in area secondaries, the low-achievers and de-motivated in trade schools, and the non-achievers and illiterate students into opportunity centres, where they are offered remedial primary education.

In this article I will focus on one of the ways in which policy-makers in Malta attempted to cater for low-achieving students by offering an alternative form of education, trade schooling. In order to be able to examine some of the ways in which these schools ultimately worked against the interests of their clientele, it is first necessary to briefly portray the socio-economic and political setting that saw the rise of vocational schools in Malta, at a time when most other countries, developed and developing, had given up on such forms of educational provision (Benavot, 1983).

\section{The Context}

Trade schools were in fact set up as post-middle school institutions in Malta in 1972 by a Labour Government intent to meet two, ultimately contradictory challenges, economic and ideological (Sultana, 1992, 1993). The first referred to the economic necessity of providing a new cadre of skilled and semi-skilled workers who would be instrumental in attracting foreign industrial investment, and in moving Malta away from a dangerous over-reliance on defence spending by the British. Malta had obtained political independence from Britain in 1964, but was still economically dependent on generous loans and grants, and on rents paid for the utilisation of the islands by the United Kingdom and NATO as a military base. Soon after the end of the second world war, however, it had become clear that British defence interests in the Mediterranean had waned, and that its policy of defence cuts world-wide would badly effect Malta. Successive governments had embarked on a desperate attempt to develop a manufacturing base, attracting, with varying degrees of success, light and labour-intensive industries, in such fields as textiles and clothes manufacture (Baldacchino, 1993). These were attracted to Malta by the 
supply of cheap and docile labour. Tourism too became one of the growth industries in Malta (Inguanez, 1994).

After the elections of 1971, the Labour government embarked on a series of reforms which were to challenge the economic, social and educational structures that had put into place by a more conservative Nationalist government (Zammit, 1984). Its educational agenda stressed a left-wing ideology which entailed a whole package of innovations such as the removal of the tripartite secondary school system, the banning of inter- and intra-school streaming at the middle school level, the replacement of examinations by continuous informal assessment, and the introduction of a new emphasis on social class mixing, the privileging of manual labour, and the withdrawal of support of private schools. Measures were taken to make tertiary education more accessible to students from working class backgrounds, and at all levels, education was to promote achievement rather than selection and exclusion (Sultana, 1991, 1992).

These ideological goals were, however, not to be considered in isolation from the pressing economic needs of the country. Unemployment became a serious issue due to the run-down of the British services and the worldwide economic depression. The emphasis on "offering to all [students] the opportunity to develop to the best of their ability", $[2]$ had therefore to be linked to the need "to build a new Malta, with an independent economy, based on industrial development, with a full and wise use of its manpower potential".[3] Trade schools were therefore launched in order to cater for students who, after their second year in secondary schools, felt they were either unable or unwilling to go on with academic schooling. The new vocational schools would focus on the teaching of trades, with general education taking up only $25 \%$ of class time. These schools would therefore be more useful to the country than the secondary technical schools that had been established on the British model in the late-1960s, because these had emphasised academic instruction to such an extent that they were in fact 'technical in name only'. Trade schools would thus not only attract students disillusioned with mainstream schooling by providing them with a more relevant curriculum, but they would also make a direct and essential contribution to a developing 'economy.

The success or otherwise that trade schools encountered in achieving the economic, educational and ideological goals expressed in their favour when they were set up 20 years ago has been the subject of an extensive research project which the present author designed and co-ordinated between 1989 and 1992 . In this context, only a few aspects related to the educational dimension of vocational schools, and the relationship of this to the reproduction of inequality, will be addressed. Suffice it to say that overwhelming evidence has been collected to show that Maltese trade schools have generally failed to satisfactorily achieve 
any of the goals identified above. They have failed to help the economy many students in fact find jobs unrelated to their training, or at a level which does not make use of their skills (Sultana, 1993). They have failed to encourage social class mixing and the privileging of manual labour - most vocational students are from a working class background and trade schools have a very low status within the overall educational system. And they have also failed to provide an educational service which is attractive or which, while being different, is as valuable as that offered in mainstream schools - absenteeism is very high in trade schools, and the quality of education suffers because of a number of inter-related and complex factors a few of which will be explored below.

\section{Methodology}

The Trade School Research Project (TSRP) brought the research team in contact with large numbers of students and teachers/instructors in trade schools. Quantitative and qualitative research methods used included a detailed questionnaire with 680 15-year-old trade school students, three tracer studies with 258 ex-students, in-depth interviews with 241 students, 137 teachers and instructors, and 60 industrialists, and more than 800 hours of classroom/workshop and staffroom observation in trade schools.[4] Glaser \& Strauss's (1967) grounded theory strategy informed most of the qualitative research carried out. In addition to that, documentary evidence related to the project was culled from newspapers, and files held at the Department of Education. The conclusions arrived at are therefore based on a large data bank which is reported in greater detail in Educational and National Development: historical and critical perspectives on vocational schooling in Malta (Sultana, 1992).

\section{Trade Schools and Education}

The data generated by the Trade School Research Project throw light on the quality of the educational experiences offered in vocational schools and to the way these are related to the structuring and reproduction of inequality. One way of evaluating the quality of the educational program offered to vocational students is to consider the following:

(a) the effect of having a 'separate school' within the overall structure of an educational system, especially when different educational programs enjoy different status and resource allocation, and lead to different rewards structures;

(b) the curriculum and the forms of knowledge it promotes and legitimates;

(c) the classroom processes that are encouraged in the transmission of knowledge; 
(d) the status of the expertise of teaching staff, compared with that found in other schools on the islands;

(e) the allocation of educational resources between different schools, and equipment especially so.

In this context, it is only possible to report data related to the first three of the issues mentioned above. In discussing these issues, however, it will become clear that trade schools in Malta have generally been deprived of the adequate human and material resources required to make these educational spaces truly profitable for the students occupying them. The data are placed in a comparative education context in order to show more clearly how the Malta case reflects findings of research carried out elsewhere, and to suggest that the problems identified in this article could be endemic to vocational schooling at the secondary school level and are therefore not necessarily context-bound.

\section{Separate Schools and the Construction of Inferiority}

Comparative education literature shows that the provision of a separate space for a homogeneous clientele leads to the attribution of high or low status to that establishment. When that student population is characterised by a strong working class background, carrying with it negative school experiences and a tradition of a vigorous counter-school culture, then it is likely that the separate space created to cater for such students will end up having a lower status in the overall educational system. This is to the detriment of the educational goals expressed for the program because the context which frames 'separate schooling' creates a sense of second class citizenship among both teachers and taught which militates against effective learning (Blaug, 1973).

Indeed, vocational education functions to identify a certain type of student and to stamp the student with a certain status and identity. In this sense, the concept of 'vocational education' is more like that of 'advanced placement'. It communicates a certain status and projects a certain future. And it does this not only to the school authorities and to future employers, but to the students themselves (Venables, 1967; Grignon, 1971). By such relegation to a different space, "schools send a message that some children are gifted, bright and academic and that others are average, slow, or vocational. Few students and teachers can defy those expectations" (Oakes, 1986, pp. 76-77). Students recelve the message that they are somehow 'different' and academically 'inferior', and thus the concept of self-fulfilling prophecy works, in the case of vocational schools and tracks, at the institutional level.

The most profound and thorough study which documents how these processes take place in vocational schools has been carried out by Claude Grignon within the context of French trade schools. The latter are constructed as a subordinate sector of education where the 'strong 
discourse' of traditional academic schooling and of elite classes emphasises the abstract, the theoretical and questioning ambiguity, while in opposition is the 'weak discourse' of certainty and manual/practical activities of the Lycée d'Enseignement Professionel (LEP). The technical culture of the LEPs stand midway between the two, valuing the former through the inclusion of some elements of the strong discourse (academic subjects, teachers, and theoretical aspects of trades) but at the same time separated because of its rejection of ambiguity and uncertainty. In addition, the interplay between these three elements is symbolised by the different status of teachers and instructors, who utilize different pedagogic approaches with their students. Thus, instructors tend to be 'chummy', and adopt an informal, matey yet authoritarian style. Teachers of the general subjects are distant and formal. Those who teach the theoretical aspects of technical instruction embody the technical culture, and hence are abstract, theoretical, but precise.

The interiorization of the differential status with which the three different discourses of pedagogy - strong, weak, and technical - are endowed with is reflected in the way the more motivated students respect but do not adopt the first, reject the second, and embrace the third. It is seen in the differential status attributed to the vocational subjects, with an informal hierarchy where the wholly manual are at the bottom, and where the more 'technological' trades, such as mechanical and electrical engineering, have greater prestige than joinery, for instance. Indeed, Grignon argues that the hidden function of 'general education' is to signal to students their inability to handle elite culture.

\section{The Construction of Inferiority in Malta's Trade Schools}

There is no doubt at all that trade schools in Malta are considered to be inferior educational spaces, and that this low status rubs off not only on students but on teaching and administrative staff. Teachers and heads interviewed in connection with the TSRP were of the opinion that trade schools were the 'Cinderella' of the educational system and felt abandoned by the Department of Education for whom they were the 'after thought'. There was not a structure to cater specifically for their needs, had hardly any visits, in the case of boys' schools, from education officers, and lost staff through transfers to mainstream schools when teachers were missing there. That meant that they had to go without teachers themselves, and when new subjects were introduced following the implementation of the National Minimum Curriculum, staff were obliged to teach subjects which they had not even studied.

Compared with junior lyceums, for instance, they felt that their premises were in a terrible state, with some classrooms and tollets reminding them of 'Beirut'. There was a general feeling of disillusionment at the fact that trade schools were used as a 'dumping ground' for 
unmotivated, unachieving students, and then blamed for having high rates of illiteracy and absenteeism: "Trade schools have a bad name, a label, call it what you wish ... and the children who come here are already labelled as delinquent, when in fact they come from the secondary school like that".[5] Teachers wanted the trade school uniform for boys to be changed, since its colour indicated the present and future blue-collar status of students; they wanted a better quality student and were angry at the way the problematic children were channelled out of mainstream secondary schools into their classrooms. Interviews with teachers in secondary schools and junior lyceums indicated that was the basic view they held regarding the function of trade schools: "It's a blessing that there are those trade schools! God forbid that they are removed, because that's the only way the weeding process can take place".

The lower status of manual and practical study was signalled in a multitude of ways. Subjects, as in the Grignon study referred to above, enjoyed a different status according to their content of 'academic' study, so that upholstery and tile-laying, for instance, were considered to be suitable for the lowest ability students, while auto mechanical and electrical engineering, and radio and television servicing "gathered together the best brains in trade schools". Teachers of general subjects tended to sit in separate staffrooms from trade instructors. The latter were criticised for coming to school carrying their lunch and books in a shoulder bag, "as if they were dockyard workers", instead of in a 'proper' school bag or attaché case. A letter to the press complained that instructors looked 'scruffy', and that children ought not to be left "under the guidance of these hooligan-looking individuals, even for a moment".[6]

Teaching staff in trade and mainstream schools reinforced the separate status of trade school students in a number of ways. Students were told what was appropriate and realistic to achieve and aspire for. The TSRP ethnographic data bank reports several instances of such processes, with students being warned not to 'fantasise' or 'dream', but to be aware of limitations. Trade school students were constantly reminded that they were not eligible for the elite culture, and for jobs within that range. As one teacher told her students on the first day of school: "We have not come to this school to become teachers, or a manager's secretary, or a clerk. This school prepares us for other kinds of jobs ... manual work".

The more dedicated among the teaching staff saw themselves as welfare and social work officers rather than as teachers, for these students were considered to be not only difficult and problematic, but also as coming from 'broken families', or from parents who cared little for their educational progress. Teachers thus often constructed students within a deficit and pathological discourse, and either struggled to build a communicative relationship with them or else, and more commonly, became frustrated and ended up hitting out in anger: "With these kids, you 
spit in the air and it falls back in your face. These are the worst of the worst of the worse lot". Teachers believed that trade school students had a very brief concentration span. Scientific labels were used liberally by teachers to justify the low expectations they had for their students: "I think that many of the children are dyslexic ... or perhaps they're emotionally unstable".

Trade school students were very much aware of their position in the hierarchy of status meted out by the educational system. That status followed them in their out-of-school life as well, since certain leisure facilities on the islands, such as disco halls, closed their doors to students known to be from trade schools. These students greeted the interest shown in them by researchers on the TSRP with incredulity, saying "If you're an inspector, don't come to see us because we're stupid!". or ".You can't possibly be interested in us". They were keenly aware of their position in the school system in Malta, and of the implications of that for the future: "We're all heading for the factories ... That's where we'll all end up ... We're no good with our heads".

The message regarding their inferior status had started being transmitted in the primary school and was being sustained in trade schools, occasionally covertly, but often indirectly. They generally integrated the belief that there was a dichotomy between 'manual' and 'mental' work, and that they were good at the former but not at the latter. In the words of one student, "I was not good at school, so I chose trades ... Since I'm not good at school, I don't know much else". Another explained that she preferred to work with her hands, since she felt she was not good at English and "those sorts of subjects". "I used to lose heart ... I put it into my head that I was good for nothing. Even when teachers asked me to speak in class, l'd start stammering ... l'm not good at school".

Given these conditions, the surprising fact is not that students gave up on learning, and left school as early as possible,[7] but that some, albeit a minority, survived the labelling and 'weeding out' process and made it to the fourth year and into further (technical) education.

\section{The Curriculum}

One of the most fruitful methods of analysis of curricula that has been developed in the past three decades refers to the political economy of knowledge, an approach which is especially fruitful when, as in this case, the declared intention is to evaluate educational provision in terms of the value of equity. In other words, when comparing and contrasting the curriculum packages offered to vocational as against mainstream schools, the question must be asked as to whether "the school system programs the same type of knowledge in all sections, apportioning it unequally, or does it assign different types of knowledge relating to different spheres of social activity?" (Tanguy, 1985, p. 22). 
Comparative literature has in fact pointed out that there are a number of key differences in the programming of a curriculum for the technical track when compared with the academic one. There is generally more time allotted for studies within school rather than outside, with reference to the number of hours in school per week, the number of weeks in a school year, the number of school years, and the number of hours of compulsory schooling. The academic track takes up fewer school hours, and in fact homework is used to transfer learning to the context of the family. The assumption is that the family understands and has the intellectual and cultural models proposed by the school. The technical track works differently, for here practically all the teaching is directed towards the students in the context of the school. While the homework assignments for academic track students encourage a relatively dynamic and critical attitude towards knowledge, with individuals being asked to take charge of their own learning and to manage their own time, with the help of understanding parents, teachers in the technical schools seem to take for granted that the cultural and material conditions in the home which would sustain and complement the learning that takes place in the school are in fact missing.

The transfer of school work to the home creates, or better sustains and reproduces different competencies and personal qualities - such as self-management, autonomy, creativity, the production of knowledge which are functional to the future occupational destinations of the academic students. The latter, generally middle-class students are schooled for competencies required by middle-class jobs, while technical students, often from working-class origins, are schooled for competencies required by blue-collar jobs.

This differential socialisation is achieved through other ways as well. Thus, for technical students, the stress laid by the curriculum is on the skills required by production, so that technique is divorced from an understanding of the way these skills are linked to the social sphere since elements such as philosophy, history, geography and social sciences are either excluded from instruction, or not included as examination subjects, hence implying that they are not vital for technicians. "This exclusion of societal concerns from technical curricula leads to a neutralization of techniques and a reification of social production. Industrial-technical education seems totally rooted in the present without reference to the past; man [sic] is perceived as an object rather than as a subject" (Tanguy, 1985, p. 27).

On the other hand, the emphasis in the academic schools is directed towards the mastery of the fundamentals of institutionally constituted scientific knowledge, and tends to "neglect the question of their application and remains rooted in legitimate culture" (Tanguy, 1985, p. 27). But above all, the academic schools, through their emphasis on the knowledge of man, transmit those qualities which are a key to the 
culture of intellectuals, namely "the ability to perceive oneself as a whole and the world as a whole, the ability to relate the specific to the general ... to disassociate themselves from what is tangible, concrete and particular in order to approach theory, formalization, and general principles [which allows them] to detach themselves from reality and strive towards an abstract thought embracing both the past and the future" (Tanguy, 1985, p. 28).

These curricular differences tend to construct two dominant modes of thought, idealism and mechanistic materialism, where "the former allows the individual to evolve in the realm of ideas, representations, and values but leaves him [sic] totally helpless in the realm of material objects and techniques; the latter gives him [sic] an awareness of the material world but tends to depoliticize the social sphere, treating it in purely technical terms" (Tanguy, 1985, p. 32).

Thus, the technical student, unaware of the why and the wherefore of techniques, does not learn to master them but only to use them. The focus is on the facts, such as operating instructions; on findings and formulae; and on processes detached from their principles. This transmission of different categories of knowledge is one of the mechanisms by which the relations of dominance are achieved, because the emphasis on technique leads to "the presence on the market of a labor force dispossessed of general social skills but equipped with the particular qualities necessary for production: familiarity with machines, familiarity with technical jargon, acceptance of the idea that techniques are natural phenomena, and, thereby, acceptance of the necessity of the established productive order" (Tanguy, 1985, p. 32).

In addition to this, Grignon (1971) has argued that the constant appeal to material reality which can be touched with the hands leads to a specific construction of the world and of social processes in terms of a technical problem or challenge for which, given that the correct methods are employed, there is always a solution. This solution is moreover found by the individual isolated from his or her social context - hence, problems of differential access to power, or of the possibility of different points of views held by different participants in a social situation, are excluded in this technocratic problem-solving approach encouraged by the prevalent instructional discourse in technical schools. The idea that there is always 'one best way' of solving a problem leads students to generalize this mechanistic disposition of mind to the sphere of social relations where the morality of the technical processes, the certainty of things, applies as well. Irony, scepticism, calling everything and everyone into question, including oneself, is part of the 'strong' discourse of the abstract, theoretical and questioning culture of the academic schools and the dominant social classes. For the weak discourse of the trade schools, it is certainty, perseverance, patience, single-minded application, neatness and 
precision that are encouraged and fostered through such tasks as filing for hours on end, or technical drawing.

\section{The Curriculum in Maltese Trade Schools}

There is a Maltese version of the Aristotelian distinction between 'training' and 'education', where the former leads a person to have the skills to carry out a task, without having an understanding of the nature and significance of the task itself, while education develops the ability to address the social and moral implications of otherwise technical activity (Feinberg \& Horowitz, 1990). The difference between strong and weak educational discourse, the former as present in academic schools, the latter in technical schools, does obtain locally, although certain important caveats must be made. In Maltese mainstream schools, one can note a subservience of curricula and pedagogy to the requirements of examinations, with parents, students and teachers giving great importance to credentials. The 'diploma disease' is therefore rife in a situation where educational development has outstripped economic growth (Dore, 1976). This often leads to a weakening of the strong discourse of critical evaluation and discussion, and the emphasis is therefore placed on directed learning, which in many instances is closer to 'training' than 'education'. In the case of the school-to-work curriculum, for instance, the division of labour, the hierarchical status and wage structures, the emphasis on extrinsic rewards, one and all generally have a hegemonic tenor, whether presented in the more academically-orlented junior lyceums or in trade schools (Mifsud \& Mallia, 1991).

However, an analysis of the curriculum packages in both types of schools reveals certain crucial differences. Trade school students have only one $\mathbf{4 5}$ minute lesson in social studies per week, while junior lyceum students can choose to spend up to four hours a week studying various aspects of their social environment. Consequentially, the trade school curriculum is a watered down version of the junior lyceum social studies syllabus. The emphasis in trade school social studies syllabus is on the topic 'work', which takes up to half the academic year in the case of boys in their second year of trade schooling, and one-quarter in the case of girls. The same topic takes up to one-sixth of the year in the junior lyceums. In addition, the trade school syllabi are more akin to information geared at moulding a 'good citizen', while the junior lyceum syllabus is more amenable to the raising of questions and to critical debate. Junior lyceums treat subjects like democracy, different political systems, unemployment, while trade schools focus on such topics as fanaticism and sports, choice of career, and so on. Even the mode of assessment differs, with trade school students being encouraged to fulfil the 25\% dedicated to project work by looking at mass culture, taking part in carnival activities, sports, band clubs and drama, while junior lyceum 
students are invited to take part in community service, to train in leadership and organization skills, to develop artistic abilities, and to participate in competitions, civic campaigns, and so on.

The portrayal of trade school students as different, and as a special group which cannot have access to the prestigious culture available in mainstream schools, has, as suggested earlier, been present from the foundation of vocational schools, even though that construction was contested and modified over the years. Thus, trade school students were first offered a curriculum with $75 \%$ 'practice' and $25 \%$ 'theory'; this was then modified to $50 \%$ for each, then to $60 \%$ and $40 \%$, and most recently to a reversal, with $40 \%$ for 'practice' and $60 \%$ for 'theory'. The changes are important and significant in so far as they signal different political attitudes towards the construction of a 'different class of student'. In all cases, however, a differentiated curriculum serves to 'warm up' some to invest in further education and to 'cool out' others from a similar effort (Cicourel \& Kitsuse, 1963). It is not being suggested that there is a conspiracy against students in trade schools, but rather that seemingly innocent processes, some of which are well intentioned on the part of teachers, end up having a negative effect on the educational development of students. Homework, for instance, was hardly ever given; but this was not necessarily out of a lack of commitment on the part of teachers, but because the latter knew that there was no chance that students would do the work set.

In an attempt to make the curriculum relevant and attractive, teachers were observed diluting syllabuses. In addition, the utility of subjects was justified by referring to their applicability to the future roles students would play in life and in the workforce. A home economics teacher, for instance, encouraged her students to pay attention to the lesson by telling them that "What we are doing is for your own good. Do you want to grow up and not even know how to cook for your husband? He'll come back from work and find nothing ready. That's how trouble starts". Pupils however complained that their intelligence was not being respected, and that ultimately, a lot of what they did in class was a waste of time.

\section{Classroom Processes}

Indeed, if we take a close look at the classroom processes and instructional methods used by the more dedicated teachers in trade schools, we discover a more insidious and hidden way in which student learning was undermined. Ethnographic studies of knowledge transmission in different schools which cater for different social classes, such as those of Anyon (1981) in New Jersey and Da Silva in Brazil (1988), suggest that students are differentially socialised in schools, promoting through the pedagogic relationship developed, tasks set, and mode of 
control exercised - those personality traits which are functional for the future class and occupational destinies of students.

Similar evidence emerges from qualitative studies which observe classroom processes in vocational tracks (Sultana, 1989) and schools. Claus (1990) for instance reports that the vocational teachers he studied reproduced the work relations and expectations of the shop floor, with frequent reference to the realities of work in order to have students co-operate by attending regularly, being punctual, neat and tidy, as well as banning horse play. Aware of vocational students' dislike of bookwork, teachers negotiated with students, asking for good behaviour in return for a slackening of academic content, with as little writing, testing, reading and challenging intellectual work as possible. The students had taken the vocational route seeking a more relaxed and entertaining classroom than that offered in mainstream schooling, and since teachers allowed socialising in return for order and co-operation, educational objectives were frequently compromised for students were allowed to divert the flow of the class. While teachers often responded to students' needs out of kindness and a sense of humane commitment, the lowering of standards did not help students expand their views of themselves and their potential, and ultimately reinforced their resistance to academic instruction and their 'destinies' to working class labour. Teachers made most of the key decisions for their students, handled most of the difficult problem-solving situations, doing things for students with the intention of minimising the latter's frustration and resistance and of protecting them from a sense of failure. While on the one hand this could be considered to be a positive aspect of student-teacher relationships, it, on the other hand, fostered a dependence on superiors and an avoidance of analytical thinking and decision making.

\section{Classroom Processes in Malta's Trade Schools}

Most of the ethnographic data available on classroom processes in vocational schools in Malta suggest very strongly that teachers often dilute the curriculum in order to win students' cooperation. The TSRP data bank is replete with references to students being allowed to get away with behaviour which would have been severely reprimanded in the general schools. Vocational students were allowed to read their love story books during lessons as long as they remained quiet, for instance. They daydreamed, slept, or just stared passively. Students got away with arriving $\mathbf{1 5}$ minutes late for a lesson between periods or after recreation time, and with pretending to get lost and not being able to find where their lesson was. Teachers negotiated with students to finish their lessons early, to tell stories, to discuss life concerns, to play word games and so on in return for peace and quiet in the classroom. All sorts of repetitive exercises were given to students for the same reason, ranging from 
scraping graffiti off desk tops, to copying from notes, textbooks and blackboards in order to pace and control behaviour. Students often pointed out the uselessness of this: "But this is useless, Sir ... copying down all this! What do I care if this will crop up in exams?! As if I'm going to turn up for the exams!".

In addition to this, copying the same phrase over and over again was a typical punishment used by teachers in trade schools. Thus, out of 40 hours of classroom observation, two of the researchers on the TSRP reported that eight were spent in "doing copies". On one occasion, a whole lesson was spent copying out "I must wait in silence" 200 times (Azzopardi \& Bondin, 1991, pp. 90-91).

\section{Conclusion}

Trade schools therefore, like most other spaces created within schools systems which purport to cater for the special needs of the 'non-academic', end up 'cooling out' some from an investment in education. The very fact they exist as separate schools provides the 'correct' conditions for the 'academic' students to 'warm up' to a differentiated curriculum, where they can achieve unhindered by the 'unable'. This article suggested that these effects are not necessarily the result of a conspiracy against specific groups of students in trade schools, of a group of elite trying to undermine the working class. Rather, seemingly innocent processes, some of which are well intentioned on the part of policy-makers and teachers, end up having negative educational effects on students. In addition, the ideological distinction between mental and manual work, and the differential status accorded to these in the labour market, have real consequences on the world of schooling. As Apple has pointed out, the existing patterns of productive relations among individuals and social groups will 'naturally' generate actions that lend support to the allocation and socialisation of students into unequal productive relations. Apple (1978, p. 385) argues that "given the extant economic and political forms which now provide the principles upon which so much of our everyday lives are organised, this reproductive process is a 'logical necessity' for the continued maintenance of an unequal social order. The economic and cultural imbalance follows 'naturally'".

There is something important to be learnt from the Maltese experience. The 'new vocationalism' which constructs schools as deficient in the preparation of youths for the world of work contains within it the seeds of a pseudo-solution that has been tried in the post-war period and has failed - and which we in Malta are still struggling with. Logically, the tightening of the bonds between school and work (Watts, 1985) leads to calls for a more vocationally-specific curriculum, and with the legitimation crisis (Habermas, 1976), the temptation to channel unachieving and 
behaviourally problematic students - overwhelmingly from the working class - into such spaces will be great. The reasons will be much the same as those given for the setting up of industrial schools in the early 19th century. But the results, as witnessed by the Maltese case-study presented above, will also be much the same: that is, the creation of lower-status tracks and/or schools for low status students who will be offered an inferior, diluted form of education, and which, 'good intentions' and all, will lead to the reproduction of inequalities from one generation to the next. As Bernstein (1971, p. 58) noted with regards to moves to include technical elements and a 'relevant' curriculum in the curriculum, these were often "not simply for the transmission of educational knowledge, but for the purposes of social control of forms of deviancy; and that usually occurs with the 'less able' children whom the school has given up educating".

\section{Correspondence}

Dr Ronald G. Sultana, Faculty of Education, University of Malta, Msida MSD 06, Malta.

\section{Notes}

This is a revised version of a paper first presented at the first European Conference on Educational Research at the University of Twente, Enschede, Holland (June, 1992). Thanks are due to the comments made by anonymous referees on an earlier draft of this paper.

[1] Malta is made up of a group of small Islands, three of which are inhablted. It lles in the middle of the Mediterranean, 93 kilometres south of Siclly, and 290 kilometres north of the African coast. It has a total population of around 350,000, and galned its independence from Britain in 1964.

[2] Agatha Barbara, the Minister of Education, during her education budget speech, dellvered on the 23 May 1972 and reported in full in the Orizzont, 29 May 1972, p. 7.

[3] As note 2, p. 7.

[4] The research team was made up of graduate and undergraduate students following courses in the sociology of educational development at the Unlversity of Malta. The qualitative material is kept in the TSRP data bank, and most of this has been reported in a number of dissertations submitted to the Faculty of Education. The most relevant to this particular article are the studies carrled out by Azzopardi and Bondin (1991), Costa and Buhagiar (1993), Fenech (1991), and Mifsud and Mallia (1991).

[5] Quotations are from intervlews kept in the TSRP ethnographic data bank. In keeping with Glaser and Strauss's grounded theory strategy, quotations are representative of similar statements and issues raised by other informants, and are therefore not anecdotal.

[6] Letter to The Times of Malta, 4 February 1992. 
[7] Trade school boys and girls absent themselves for 30 and 50.5 days respectively out of a total 148 days they should attend in a year. That amounts to an average absence rate of $24 \%$ and 33\% (Scicluna Calleya et al, 1988).

\section{References}

Apple, M.W. (1978) Ideology, reproduction and educational reform, Comparative Education Review, 22, pp. 376-387.

Anyon, J. (1981) Social class and the hidden curriculum of work, Joumal of Education, 162, pp. 67-92.

Azzopardl, N. \& Bondin, A. (1991) Resistance to Schooling, Unpublished BEd (Hons) dissertation, University of Malta.

Baldacchino, G. (1993) Bursting the bubble: the pseudo-development strategies of microstates, Development and Change, 24, pp. 29-51.

Benavot, A. (1983) The rise and decline of vocational schooling, Sociology of Education, 56, pp. 63-76.

Bernstein, B. (1971) On the classification and framing of knowledge, in M.F.D. Young (Ed.) Knowledge and Control. London: Collier Macmillan.

Blaug, M. (1973) Education and the Employment Problem in Developing Countries. Geneva: ILO.

Cicourel, A.V. \& Kitsuse, J.N. (Eds) (1963) The Educational Decision-Makers. Indiana: Bobbs-Merrill.

Claus, J. (1990) Opportunity or Inequality in vocational education? A qualitative Investigation, Curriculum Inquiry, 20, pp. 7-39.

Costa, D. \& Buhaglar, M. (1993) Teachers' Vlews on Trade Schools, Unpublished BEd (Hons) dissertation, University of Malta.

Da Silva, T. (1988) Distribution of school knowledge and social reproduction in a Brazilian urban setting, British Joumal of Sociology of Education, 9, pp. 55-79.

Dore, R. (1976) The Diploma Disease. London: Allen \& Unwin.

Feinberg, W. \& Horowitz, B. (1990) Vocational education and equality of opportunity, Joumal of Curriculum Studies, 22, pp. 188-192.

Fenech, D. (1991) Phantoms of the Classroom: why students stay away, Unpublished BEd (Hons) dissertation, Unlversity of Malta.

Glaser, B.G. \& Strauss, A.L. (1967) The Discovery of Grounded Theory: strategies for qualitative research. Chicago: Aldine.

Girgnon, C. (1971) L'Ordre des Choses. Parls: Editions de Minuit.

Habermas, J. (1976) Legitimation Crisis. London: Heinemann.

Inguanez, J. (1994) Tourism in Malta: rupture or continuity?, in R. G. Sultana \& G. Baldacchino (Eds) Maltese Society: a sociological investigation. Msida, Malta: Mireva Publications.

Mifsud, M.J. \& Mallia, M. (1991) School Bells and Punchclocks: the ideology of work in Maltese schools, Unpublished BEd (Hons) dissertation, University of Malta. 
Oakes, J. (1986) Beyond tinkering: reconstructing vocational education, in G.H. Copa, J. Plihal \& M.A. Johnson (Eds) Re-Visioning Vocational Education in the Secondary School. Minnesota: Minnesota Research and Development Center for Vocational Education.

Scicluna Calleya, S., Sultana, R.G. \& Zammit, R. (1988) Absenteeism in Trade Schools. Guidance \& Counselling Services, Department of Education, mimeo.

Sultana, R.G. (1989) Transition education, student contestation and the production of meaning: possibilities and limitations of resistance theories, British Joumal of Sociology of Education, 10, pp. 287-310.

Sultana, R.G. (1991) Social class and educational achievement in Malta, in R.G. Sultana (Ed.) Themes in Education: a Maltese reader. Msida, Malta: Mireva Publications.

Sultana, R.G. (1992) Education and National Development: historical and critical perspectives on vocational schooling in Malta. Msida, Malta: Mireva Publications.

Sultana, R.G. (1994) Vocational schooling and economlc development: a Maltese case study, Intemational Joumal of Educational Development, 14, pp. 75-87.

Tanguy, L. (1985) Academic studies and technical education: new dimensions of an old struggle in the division of knowledge, Sociology of Education, 58, pp. 20-33.

Venables, E. (1967) The Young Worker at College. London: Faber.

Watts, A.G. (1985) Education and employment: the traditional bonds, in R. Dale (Ed.) Education, Training and Employment: towards a new vocationalism. London: Pergamon.

Zammit, E.L. (1984) A Colonial Inheritance: Maltese perceptions of work, power and class structure with reference to the Labour Movement. Malta: University Press. 